\title{
Dynamic crushing behavior of closed-cell aluminum foams based on different space-filling unit cells
}

\author{
S. Talebi ${ }^{1} \cdot$ R. Hedayati ${ }^{2}$ (I) $\cdot$ M. Sadighi ${ }^{1}$
}

Received: 22 January 2021 / Revised: 2 May 2021 / Accepted: 20 May 2021 / Published online: 5 June 2021

(c) The Author(s) 2021

\begin{abstract}
Closed-cell metal foams are cellular solids that show unique properties such as high strength to weight ratio, high energy absorption capacity, and low thermal conductivity. Due to being computation and cost effective, modeling the behavior of closed-cell foams using regular unit cells has attracted a lot of attention in this regard. Recent developments in additive manufacturing techniques which have made the production of rationally designed porous structures feasible has also contributed to recent increasing interest in studying the mechanical behavior of regular lattice structures. In this study, five different topologies namely Kelvin, Weaire-Phelan, rhombicuboctahedron, octahedral, and truncated cube are considered for constructing lattice structures. The effects of foam density and impact velocity on the stress-strain curves, first peak stress, and energy absorption capacity are investigated. The results showed that unit cell topology has a very significant effect on the stiffness, first peak stress, failure mode, and energy absorption capacity. Among all the unit cell types, the Kelvin unit cell demonstrated the most similar behavior to experimental test results. The Weaire-Phelan unit cell, while showing promising results in low and medium densities, demonstrated unstable behavior at high impact velocity. The lattice structures with high fractions of vertical walls (truncated cube and rhombicuboctahedron) showed higher stiffness and first peak stress values as compared to lattice structures with high ratio of oblique walls (Weaire-Phelan and Kelvin). However, as for the energy absorption capacity, other factors were important. The lattice structures with high cell wall surface area had higher energy absorption capacities as compared to lattice structures with low surface area. The results of this study are not only beneficial in determining the proper unit cell type in numerical modeling of dynamic behavior of closed-cell foams, but they are also advantageous in studying the dynamic behavior of additively manufactured lattice structures with different topologies.
\end{abstract}

Keywords Lattice structure $\cdot$ Finite element modeling $\cdot$ Closed-cell foam $\cdot$ Impact $\cdot$ Energy absorption

\section{Introduction}

Metallic foams are often produced from the solidification of a molten metal from which gas bubbles are dispersed [1]. High-porosity lightweight metallic foams combine excellent mechanical and physical properties including high specific strength, high stiffness, appropriate energy absorption, and low thermal conductivity [2]. Metallic foams are capable of

R. Hedayati

r.hedayati@tudelft.nl; rezahedayati@gmail.com

1 Department of Mechanical Engineering, Amirkabir University of Technology, Tehran, Iran, Hafez Ave, 1591634311

2 Department of Aerospace Structures and Materials, Faculty of Aerospace Engineering, Delft University of Technology (TU Delft), Kluyverweg 1, 2629 HS Delft, The Netherlands dissipating a high amount of energy during plastic deformation [3]. This has resulted in employing metallic foams in many industries such as automobiles, aerospace, and packaging [4]. Metal-based foam scaffolds are selected as bone/ cartilage implants subjected to load-bearing conditions [5]. Utilizing metallic foams in automobile hoods and bumpers decreases the pedestrian head injury in collisions [6].

Many numerical and experimental studies have been conducted to investigate the mechanical and physical behavior of metallic cellular materials [7-13]. The resistance of aluminum foams against projectile penetration has been studied analytically and experimentally by $\mathrm{Li}$ et al. [7]. Using ABAQUS and based on finite element analysis, Ruan et al. [8] studied the in-plane dynamic behavior of aluminum hexagonal honeycombs. The influence of involved parameters such as honeycomb cell wall thickness and impact velocity on the localized deformation mode as well as plateau stress 
has been investigated. Silva et al. [9] introduced the nonperiodic arrangement of cell walls into honeycombs as a type of microstructural variability of two-dimensional cellular materials. The application of unit cell modeling approach for analysis of honeycomb with random variations in the arrangement of cell walls was verified by their results. Wang et al. [10] assessed the compressive deformation behavior of open-cell aluminum foams with different densities and morphologies under quasi-static and dynamic loading conditions. Their experimental results demonstrated that density, in contrast to cell size, is the primary variable to characterize the elastic modulus and yield stress of foam materials. Moreover, they showed that yield strength and energy absorption are almost insensitive to strain rate, over a wide range of strain rates. Compressive behavior of closed-cell aluminum alloy foams over a wide range of strain rates has been studied by Wang et al. [11]. According to their experimental results, plateau stress as well as energy absorption capacity are remarkably dependent on strain rate. A multiscale modeling approach has been proposed by Hedayati et al. [12] to solve crack propagation problem in additive manufacturing porous biomaterials.

Closed-cell metallic foams are a subgroup of metallic cellular materials in which closed pores are distributed within materials. Although the size of cells is important, Gibson and Ashby demonstrated that the mechanical features of foams are more related to the shapes of cells rather than their size [14]. In closed-cell foams, the amount of absorbed energy is proportional to the total surface area of the cell walls [15]. Hence, to minimize the foam potential energy, the total surface area of all cell walls must be minimized. To this end, Surface Evolver software provided by Brakke [15] may be effectively utilized to achieve appropriate geometrical patterns with minimal cell wall surface area in a constant volume. Kelvin [16] and Weaire-Phelan cells [17] are two instances of such surfaces.

The response of metallic cellular materials subjected to compression has greatly fascinated the researchers and engineers. The effect of cell geometry irregularity on the elastic modulus of a Voronoi foam produced by creating irregularity in the structure of a regular Kelvin foam has been studied by Grenstedt and Tanaka [18]. Furthermore, Grenstedt and Bassinet [19] investigated the effect of non-uniformity in the cell wall thickness on the elastic modulus of regular closedcell Kelvin foam using the boundary conditions imposed on a cell, and they concluded that the stiffness of closed-cell cellular solids is not very sensitive to thickness variations. By employing a modified representative unit cell model, Meguid et al. [20] studied the crush behavior of closed-cell metallic foams with varying spatial density distribution. Moreover, a multiple cell finite element model using the modified unit cell was developed. Their results showed that nominal stress-strain curve of quasistatic crushing of foams are in good agreement with experimental data only if the appropriate density distribution is considered. The development of a representative unit cell being capable of describing the complex geometry of closed-cell metallic foams has been also presented by Czekanski et al. [21]. Moreover, Czekanski et al. [22] developed a multi-unit-cell methodology enabling the modeling of the mechanical response of metallic foams under oblique loadings. Employing multiple unit lattices, Kim et al. [23] investigated compressive mechanical behavior of closed cell Al-alloy foam produced by melt based and powder metallurgical methods. By implementing a Gaussian distribution of relative density among the lattices and random allocation of lattices in the model, the structural heterogeneity was addressed. Furthermore, the constitutive relation for the lattice material was determined by a nondestructive instrumented sharp indentation test on the cell wall. Daxner et al. [24] studied the elastic modulus and yield surface of a foam model based on Weaire-Phelan topology. Nammi et al. [25] simulated a closed-cell aluminum foam using tetrakaidecahedral unit cell descritized by shell elements and measured its mechanical response under large strains. The results were then compared to the results of structures based on cruciform-pyramid and cubic-spherical unit cells. It was then revealed that their models predict the plateau phase of the aluminum foam more accurately. Using LS-DYNA finite element codes and rhombic dodecahedron unit cell, Hedayati et al. [26] studied the elastic and post-yielding behavior of lattice structures. By constructing several primary types of anisotropic pentamode lattices, the dependence of elastic properties of hybrid pentamodes on those of individual constructing lattices was explored by Mohammadi [27]. Ghavidelnia et al. [28] obtained accurate analytical yield stress relationships for five fundamental unit cells including BCC, hexagonal packing, rhombicuboctahedron, diamond, and truncated octahedron. Aldoshan and Khanna [29] studied the compressive mechanical behavior of carbon nanotube reinforced Al-foams under quasi-static and dynamic loading conditions. They investigated the compressive response at high strain rates using Split Hopkinson Pressure Bar (SHPB). According to their results, mechanical properties such as peak stress, plateau stress and energy absorption increased with the increase in relative density. Stress-strain behavior of closed cell aluminum fly ash foam developed through liquid metallurgy route has been investigated by Dass goel et al. [30] over a wide range of strain rates from 700 to 1950/s. Giorgi et al. [31] developed the microstructural numerical models of closed cell foam made of aluminum alloy. Two types of cells including Kelvin cell with plane and curved walls as well as ellipsoidal cell defined by random dimensions, position and orientation have been adopted as the base unit. Typical stress-strain curves were obtained by performing static tests. Impact property of the sandwich composite with aluminum foam core was 
investigated both experimentally and numerically by Han and Cho [32]. By a combination of nanoindentation experiment and numerical simulation, the cell wall material properties of Al-alloy foams have been derived by Hasan [33]. Utilizing the derived material properties in finite element analysis of foams, the existing constitutive models of closedcell Al-alloy foams have been evaluated against experimental results. Utilizing numerical methods and experimental tests, Kadkhodapour and Raeisi [34] investigated the relation between the microscale deformation and the macroscale properties of closed-cell aluminum foams. They showed that cell shape causes some changes in macroscopic material behavior, which can be explained by its effect on the pattern of deformation and local failure in the material. Liu and Zhang [35] conducted a numerical study to model the mechanical behavior of aluminum foams under compressive loading using the tetrakaidecahedrons representative volume element. The energy absorption performances of the aluminum foam filled connectors under drop-weight impact loading have been evaluated using experimental method by Wang et al. [36]. In their work, the effects of loading rate, filled aluminum foam, pleated plate thickness, and the angle between flat plate and pleated plate on the energy absorption performances of the connectors were investigated. Their results implies that the energy absorption capacity is improved by filling the connector with aluminum foam as well as increasing loading rate and pleated plate thickness. Furthermore, the numerical and analytical models were developed to predict the force-displacement responses of the connectors, which showed good agreement with the test results. Using a lightweight sandwich panel, Epasto et al. [37] suggested a novel protective mechanism (metallic foam shell-MFS). Moreover, experimental tests were performed to assess the efficiency of the suggested device against flying ballast impacts. Han et al. [38] put forward a new direction to study the fender for tripod for the aluminum foam material. Thorough investigation including maximum collision force, energy absorbed, the maximum bending moment of the fender, Von Mises stress and plastic strain were studied.

Due to geometric complexity, manufacturing methods for fabricating cellular structures with regular unit cell types were not available in the past. In recent years, the emergence of additive manufacturing techniques has made it possible to fabricate lattice structures with desired unit cell geometry [39]. The excellent properties of cellular materials have attracted special attentions. Since the properties of these structures are highly dependent on the geometry of their constituent cells, knowledge of the mechanical properties and response of these structures is of great value in both before and after of failure. Despite the introduction of a large number of unit cell types for cellular structures [40], there is no information on the dynamic behavior of most of them under impact loading, and so far, only limited and scattered studies have been performed on some cells. Moreover, no comparative studies have been performed on dynamic behaviors of lattice structures with different unit cell types. On the other hand, the connection between microstructure deformation and overall behavior of foam structures has not been studied for impact phenomenon. Therefore, in this study, the behavior of five different topologies (kelvin, Weaire-Phelan, rhombicuboctahedron, octahedral, and truncated cube) that are most geometrically similar to closed-cell foams are studied.

The goal of this study is dynamic analysis of closed-cell foams experimentally and their numerical modeling using different unit cell topologies. The aim is to find out which topologies can best predict typical compressive mechanical properties of closed-cell foams. The specimens used in the experimental test are obtained from a foam block made by casting method. The specimens are classified into three different densities. Low-velocity impact tests are performed using a drop-weight machine, and their stress-strain diagrams are extracted. FE analysis is utilized to investigate the response of closed-cell foam material. Lattice structures based on five different unit cell types are modeled and their pre- and post-failure behavior is analyzed under compression. Finally, the results of numerical modeling are compared with each other as well as with experimental results.

\section{Materials and methods}

\subsection{Experiments}

\subsubsection{Preparation of the specimens}

In the first step, closed-cell aluminum foams of the type ALPORAS were fabricated using batch casting process. The ALPORAS foams are often produced by adding the titanium hydride powder to the molten aluminum as a blowing agent. Afterwards, the foam block was cut and removed from the mold. This procedure is depicted in Fig. 1. The foam mass density was graded along the height direction such that the foam local density decreases as its distance from the bottom side increases. By measuring the dimensions and weights of the foam specimens prepared by cutting foam block, the specimens were classified into three groups of low density, medium density, and high density. The dimensions of each metallic foam specimens were $35 \times 35 \times 35 \mathrm{~mm}^{3}$, and the average pore size was $5 \mathrm{~mm}$. So, there are seven cells in each direction. The thickness of the cell walls varied between 0.1 and $0.3 \mathrm{~mm}$ depending on the local foam density. The porosity of the foam for the densities of $2 \times 10^{-4}, 3 \times 10^{-4}$ and $5 \times 10^{-4} \mathrm{~g} / \mathrm{mm}^{3}$ was calculated as $0.92,0.89$ and 0.8 , respectively. For each test configuration, three specimens were considered. 


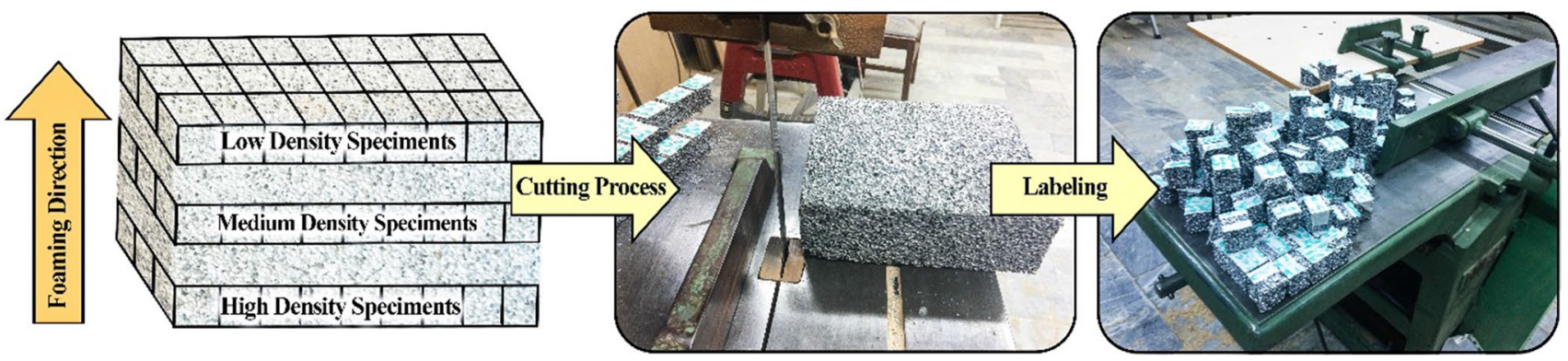

Fig. 1 Fabrication steps of closed-cell aluminum foam specimens

\subsubsection{Low velocity impact test}

To obtain the behavior of closed-cell aluminum foam under low velocity impact loading, drop-weight impact test device was used. The main components of the device included vertically guided drop weight, fixed base plate, impactor release system, accelerometer, data acquisition device, and impactor height control system (Fig. 2b). There were a number of fixed rails parallel to each other secured on the base which had the role of steering the drop weights. The weights must be attached to the device in such a way that they can fall down with minimal friction. The weights were elevated to a specific height by the electromotor attached to the release system. The impactor was a cylinder with $50 \mathrm{~mm}$ radius. The base of the device was placed on a firm foundation so that the weight could use its full energy for crushing the specimen. To obtain the required force for specimen collapse, a number of quasi-static experimental tests were performed on the specimens with densities identical to those of impact tests using a uniaxial pressure device with strain rate of $0.001 / \mathrm{s}$. By calculating the area under the stress-strain curve, the amount of energy $(E)$ required for specimen collapse was obtained. This amount of energy is accessible if the impactor experiences a free-fall motion from the height $h=E / m g$, which was approximately $0.7 \mathrm{~m}$ in the present work. The latter determined the impactor velocity right before impact by $v=\sqrt{2 g h}=3.7 \mathrm{~m} / \mathrm{s}$. For obtaining the dynamic behavior of foam specimens at higher velocities, numerical analysis was utilized. After attaching the required weight which for this test was $14 \mathrm{~kg}$, the height of the impactor was set to $700 \mathrm{~mm}$. After placing a foam specimen in the position, the weight was released by the releasing mechanism, and afterwards the data collection system stored the data sent by the accelerometers on a computer. Using the stored data, the nominal stress-strain diagram for each specimen was calculated and depicted. An accelerometer with data-acquisition accuracy of $10 \mathrm{~ms}$ was used in this research. In other words, the accelerometer recorded accelerations at a sampling frequency of $0.1 \mathrm{MHz}$. The accelerometer approximately recorded 2000 values of acceleration.
This in turn implies that the accelerometer can record impact data within a time interval of $0.02 \mathrm{~s}$. A proximity sensor was therefore utilized to initiate data acquisition. To extract stress-strain curve, acceleration values collected by the accelerometer were multiplied by the impactor mass giving the contact force between the impactor and foam specimen. The latter was then divided by the cross-sectional area of the foam specimen to obtain mean stress. On the other hand, the accelerations may be numerically integrated to obtain displacements. By dividing the displacements by the initial length of each foam specimen, the strain corresponding to each stress was computed.

\subsection{Numerical simulation}

The numerical analysis of the closed-cell aluminum foam behavior was carried out by constructing lattice structures consisting of regular unit cells. Construction of a large-sized lattice structures for the FEM analysis can be challenging. If a cell with all its walls is to be repeated in three main dimensions to create a lattice structure, each pair of neighboring cells would have shared walls. The shared walls of the neighboring cells can result in the unrealistic stiffening of the lattice structure which will result in inaccurate results. To resolve the problem and to create a cellular network of unit cells, first the unit cells were created by CATIA package (Dassault Systèmes, France) and then they were repeated in three main dimensions. The constructed lattice structures based on different unit cell types (Kelvin, Weaire-Phelan, rhombicuboctahedron, octahedral, and truncated cube) are illustrated in Fig. 3. After assembling the unit cells, the structure was examined carefully, and all the repeated walls in the common interfaces were omitted. In the next step, the constructed cellular structure was exported to LS-DYNA package (JSOL, Japan). The mechanical properties used for the FE models are listed in Tables 1 and 2. For discretizing the lattice structures, shell elements were implemented. Since the foam density is a very influential factor in determining its behavior, the densities of the constructed FE lattices have to be similar to the density of their corresponding 


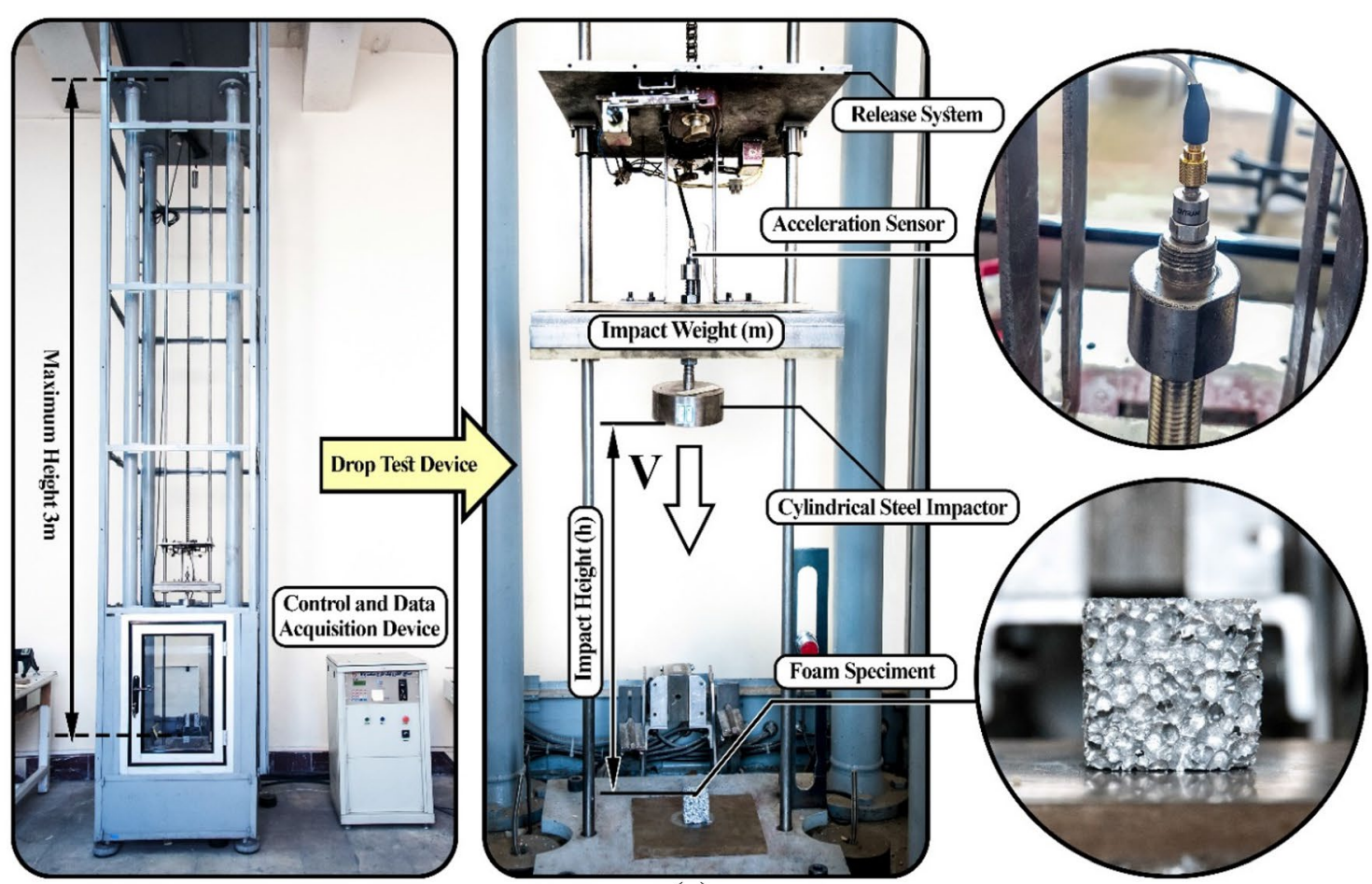

(a)
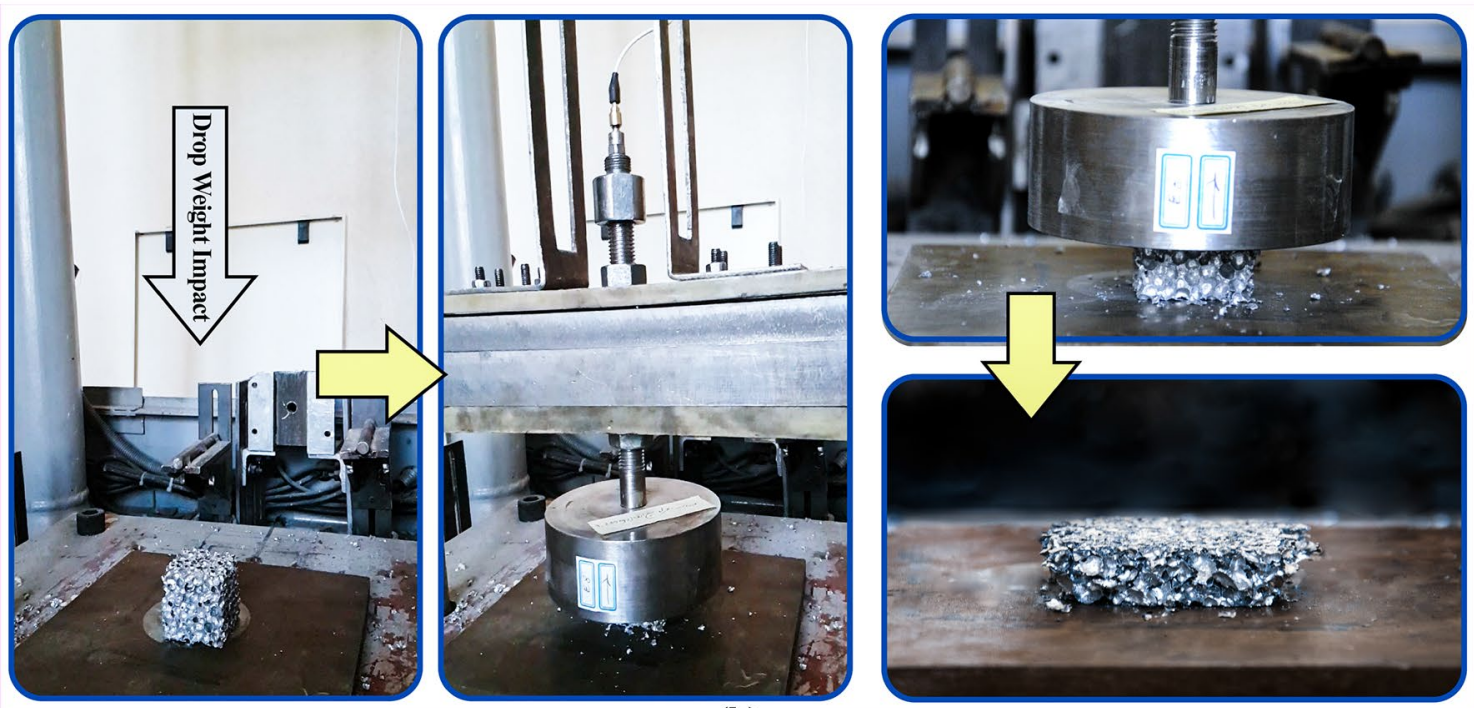

(b)

Fig. 2 a Test setup of drop weight low velocity impact. b Experimental low velocity drop weight impact test procedure

foam specimen used in the experimental tests. To attain this objective, the thickness of the shell elements of each cellular structure was determined by the density of corresponding foam specimen used in drop tests (Fig. 3).

To analyze the nonlinear behavior of aluminum foams under intense dynamic loadings precisely, the PLASTIC KINEMATIC material model (material type 3 in LS-DYNA), was employed to simulate the cell-walls, aluminum alloy. This model is suitable to model isotropic and kinematic hardening plasticity with the option of including strain rate effects. PLASTIC KINEMATIC model requires yield stress as well as tangent modulus as input parameters. In this regard, a uniaxial tension static test was performed, and yield stress of $\sigma_{y}=134.1 \mathrm{MPa}$, tangent modulus of $E_{\mathrm{tan}}=1.724 \mathrm{GPa}$ were obtained. 


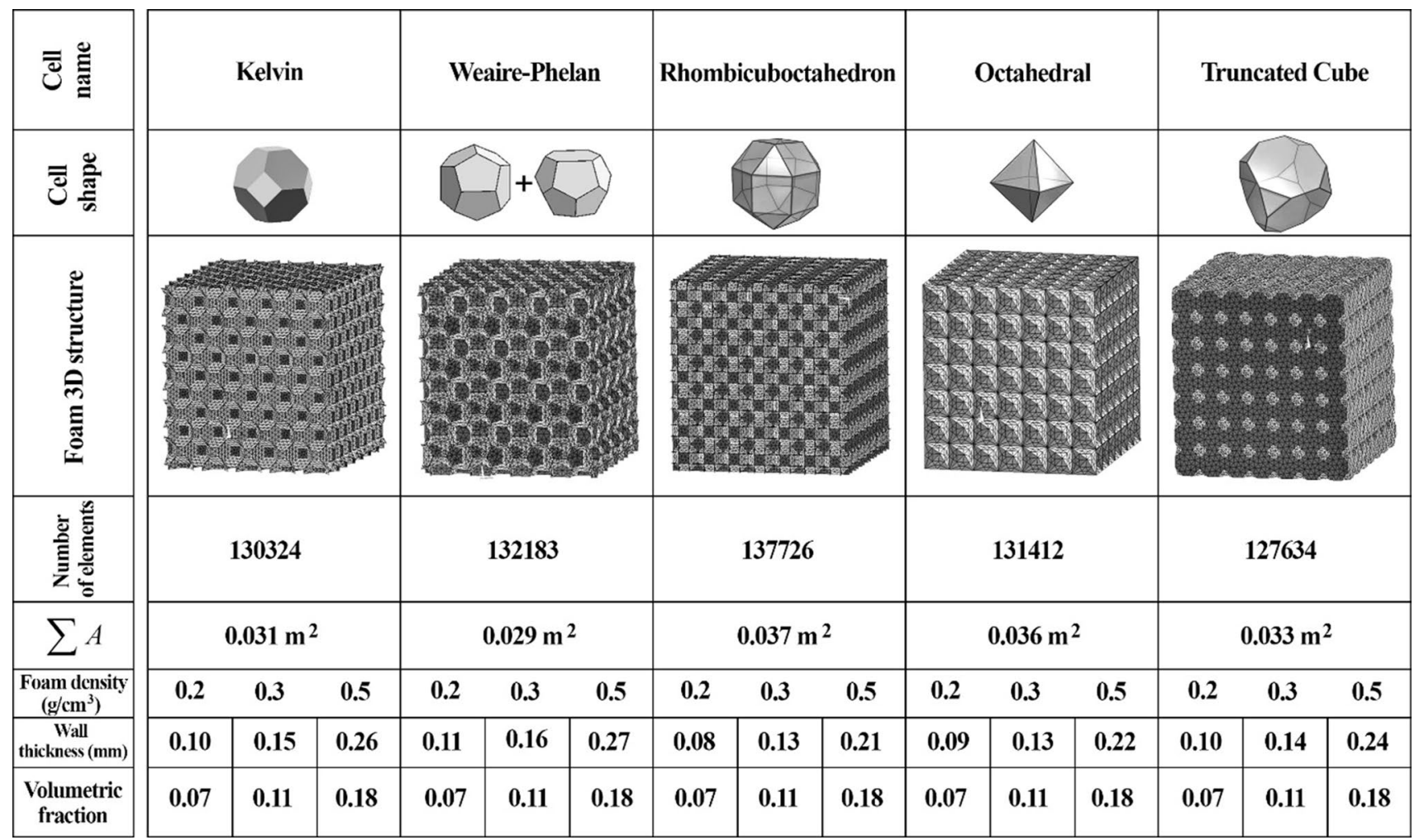

Fig. 3 FE lattice structures based on different unit cell types

Table 1 The mechanical and physical properties of the material used in the FE model for the elastic regime

Table 2 The plastic stress and strain of the material used in the FE model

\begin{tabular}{ll}
\hline Property & Value \\
\hline Density $\left(\mathrm{kg} / \mathrm{m}^{3}\right)$ & 2700 \\
Poisson's ratio & 0.33 \\
Young's modulus (GPa) & 69 \\
Yield stress (MPa) & 134.1 \\
\hline
\end{tabular}

\begin{tabular}{ll}
\hline Plastic strain & $\begin{array}{l}\text { Plastic } \\
\text { stress } \\
(\mathrm{MPa})\end{array}$ \\
\hline 134.1 & 0 \\
235.4 & 0.051 \\
256.5 & 0.098 \\
266.8 & 0.144 \\
273.7 & 0.188 \\
278.5 & 0.229 \\
282.3 & 0.27 \\
285.9 & 0.318 \\
\hline
\end{tabular}

To incorporate the strain rate sensitivity of the base material, the well-known Cowper-Symonds relation:

$\sigma_{y}=\sigma_{0}\left[1+\left(\frac{\dot{\varepsilon}}{C}\right)^{\frac{1}{P}}\right]$

was employed for the plastic deformation of the base material in the adopted 3D model where $C$ and $P$ are the Cowper-Symonds coefficients, $\dot{\varepsilon}$ is the strain rate, $\sigma_{y}$ is the dynamic stress or strength, and $\sigma_{0}$ is the quasi-static strength. Aluminum alloys generally manifest weak strain rate dependency. The Cowper-Symonds parameters for aluminum alloys were considered to be $C=6500$ and $P=4$ [41]. The steel impactor and bottom plate were treated as rigid bodies in the model. The basic material parameters were: mass density $\rho=7800 \mathrm{~kg} / \mathrm{m}^{3}$, Young's modulus $E=200 \mathrm{GPa}$, Poisson's ratiov $=0.3$. For fracture modeling, the failure strain of 0.035 is considered. The foam FE models were enclosed between a rigid plate in the bottom and an impactor on the top (Fig. 4). The element type used for discretizing the lower plate and impactor was of solid hexahedral type with eight integration points. Automatic single surface contact type was defined between the cell walls of each lattice structure. Moreover, automatic surface to surface contact type was defined between the foam on the one hand and the impactor and the lower plate on the other hand. 


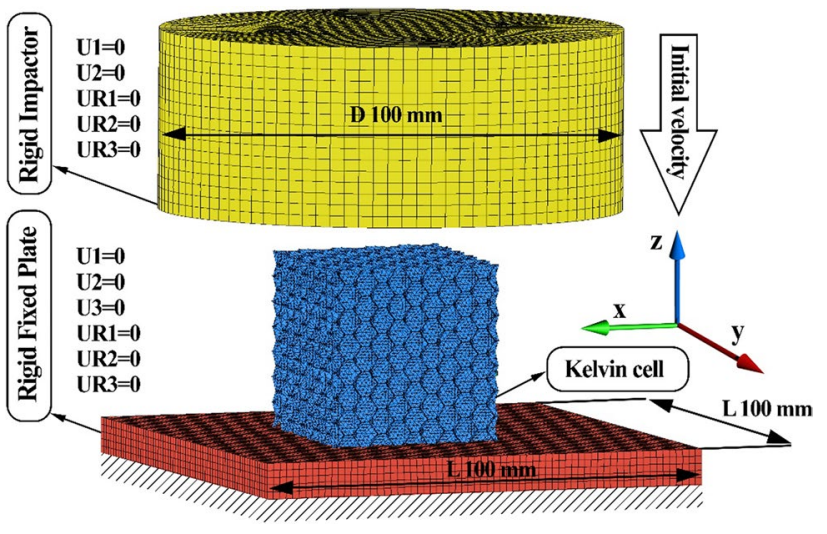

Fig. 4 FE modeling of drop test and boundary conditions
The contacts are considered frictionless. The imposed loading condition in the impact test was the initial velocity of the impactor and its weight. Different element sizes were considered for mesh sensitivity analysis and an efficient element size of $0.9 \mathrm{~mm}$ was obtained which gave good accuracy accompanied by low computational costs.

\section{Results and discussions}

\subsection{Deformation and failure analysis}

Deformation and failure modes of FE models based on five unit-cell types: Kelvin, Weaire-Phelan, rhombicuboctahedron, octahedron, and truncated cube are shown in Fig. 5.
Fig. 5 Deformation and failure modes of different lattice structures

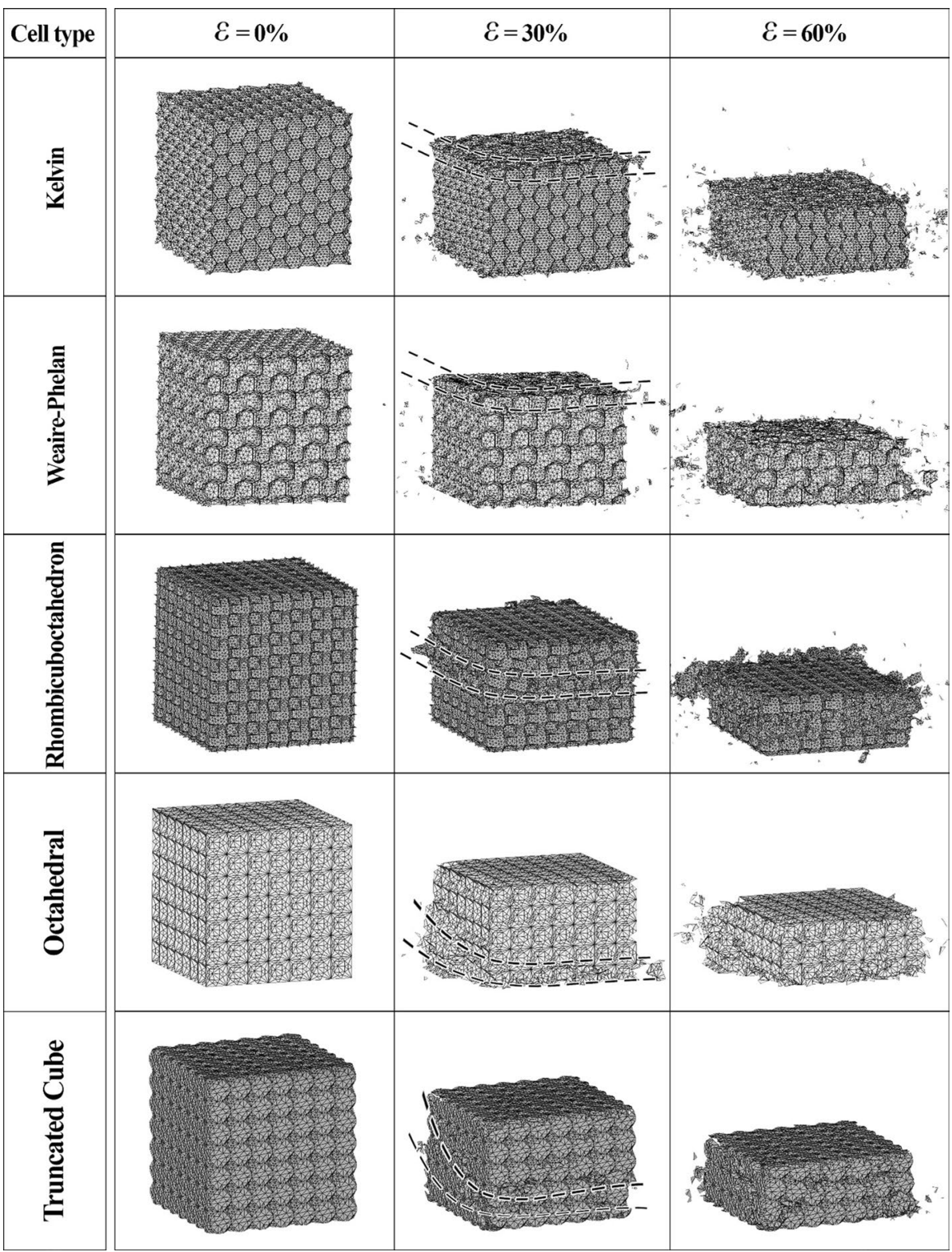


Comparing the deformations of numerical models to those of the specimens undergoing drop test reveals that the deformation of lattice structures based on Kelvin and Weaire-Phelan are remarkably similar to the deformation and failure modes of experimental tests. Failure initiation and cell collapse mechanisms are different in various cell structures which can be attributed to their different microstructures. Failure initiation highly depends on the stress distribution within foam specimens resulting from impact loading. In the experimental tests, failure of cells commenced from the upper surface where the foam specimens were in contact with the impactor. Among the aforementioned five types of unit cell, Kelvin and Weaire-Phelan cells predict failure modes similar to those observed in experimental tests, while other unit cells predict different modes of failure. For instance, in the lattices based on rhombicuboctahedron and octahedron, failure initiation and cell collapse occur in the central part of the structures. As for the truncated cube lattice structure, on the other hand, crack is initiated from the lower part of the specimens and near the supporting plate.

Differences observed in the trends of stress-strain curves as well as diversity in the modes of deformation and failure in various cell structures are a direct consequence of dissimilar micro-architectures in different unit cell types which result in different stress distributions in different lattice structures. To investigate the source of miscellaneous behaviors of cellular structures employed in the present study, the aforementioned five cell geometries were put under impact loading individually. The deformations of individual cells at different strains are depicted in Fig. 6. As it can be observed, the response of each cell type to the impact loading is dominated by the cell geometry. The modes of deformation and fracture of cells describe their impact response characteristics. For instance, the response of truncated cubic cell (Fig. 5) implies that it should have a very high initial resistant against impact loading in comparison to other unit cells. This in turn results in predicting higher values of initial peak stress as well as energy absorption capacity. Considering the deformation of Weaire-Phelan unit cell shows that this unit cell initially deforms uniformly. Due to cell wall collapse phenomenon, however, a lot of fluctuations occur in the stress-strain curve of the unit cell in the plateau region. This instability is responsible for irregular oscillations in high impact velocities. On the contrary, a more uniform pattern of deformation is observed in the case of truncated cube unit cell which explains lower oscillations present in its stress-strain curve. Layer-by-layer failure of octahedral lattice structure during impact loading, on the other hand, results in a repetition of peak stress presence in its stress-strain curve. Comparing the results of all the aforementioned lattices to the experimental data shows that the Kelvin topology can best describe the behavior of closedcell foams.
One of the important reasons for differences observed in the response of cellular structures under impact loading is the average stiffness of the lattice structure, which is determined by the stiffness of the single unit cells constructing the lattice structure. By observing the deformation of different unit cells, it can be concluded that loading a structure with a high ratio of vertical surfaces results in higher contribution of normal stress (as opposed to flexural stress) in sustaining the applied load, thus creating a high reaction force against the applied force. High contact force will result in a high initial peak stress in the stress-strain curve of the structure.

\subsection{Compressive behavior}

The stress-strain diagrams of the lattice structures based on five different unit cell types used in this study as compared to the experimental test results under low velocity impact loading and for three different foam densities of $2 \times 10^{-4}$, $3 \times 10^{-4}$, and $5 \times 10^{-4} \mathrm{~g} / \mathrm{mm}^{3}$ are illustrated in Fig. 7. Furthermore, the values of first peak stress and the energy absorption capacity both extracted from the stress-strain diagrams of the noted structures are shown in Fig. 8. As it can be seen, the results of lattice structures, although being similar, are not identical to the results of the foam specimens. This difference is caused by differences in the cell geometry and consequently different force distributions in the cellar structures. This leads to somehow different deformation and failure modes. Among all unit cell types, the results of the Kelvin unit cell are the closest to the experimental test results. Considering the higher values of first peak stress and energy absorption capacity in all the lattice structures in comparison with the experimental values shows that lattice structures (which are regular in micro-structure) are in general stiffer than the foam specimens which are composed of randomly distributed cells. The high stiffness of the lattice structures makes their stress-strain diagrams have first peak stresses with higher amplitudes as well as longer duration. As compared to manufactured specimens, the higher peak stress values along with higher plateau stress level in the lattice structures has led to lower final strain, especially in high-density foams. In other words, the impactor's energy transferred to the foam is absorbed earlier during the first peak stress and plateau region (both being relatively high). In summary, as compared to manufactured specimens, the structures resulting from the repetition of the unit cells have higher stiffness values accompanied by more uniform distribution of force in the cell walls which in turn leads to more uniform wall collapsing and hence better energy absorption capacity.

In all the foam densities, the lattice structures based on Weaire-Phelan unit cell give the lowest values of first peak stress, while the highest value of first peak stress belongs 


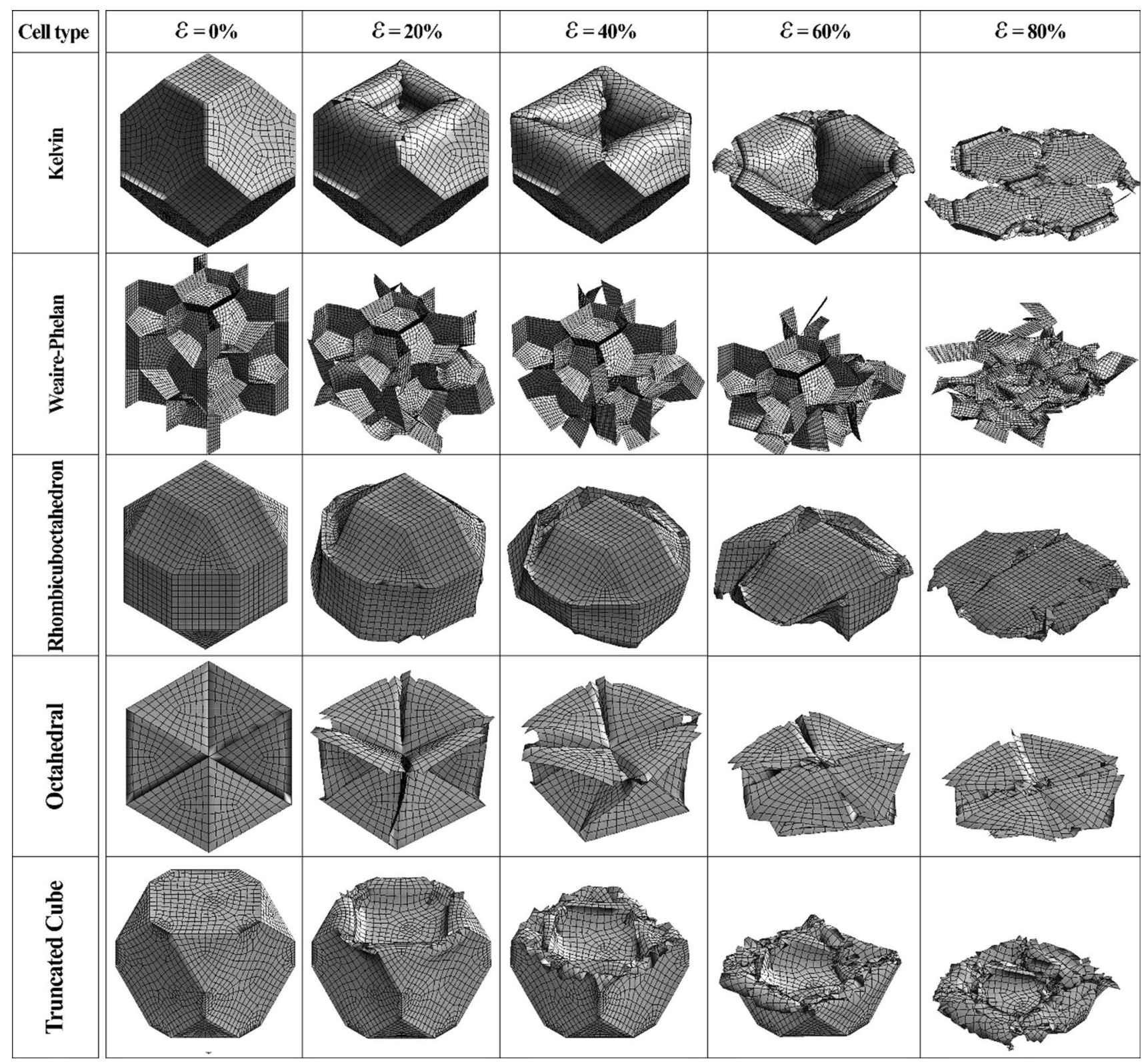

Fig. 6 Deformation and failure mode of different unit cell types

to truncated cube topology. This can be attributed to the geometry of truncated cube cell, as among all the unit cell types, this unit cell has the largest ratio of cell walls oriented parallel to the applied force direction, which means that the axial tension in this unit cell is the highest among all the unit cells. It is obvious that for the same amount of force, a wall deforms much easier under flexure as compared to pure compression. Among all the unit cell types, Kelvin and Weaire-Phelan unit cells are more similar geometrically. Consequently, stress-strain curves of Kelvin and Weaire-Phelan structures resemble each other. As expected, since both the Kelvin and Weaire-Phelan unit cells are created based on minimization of the cell wall area, the results of these structures are the closest to the experimental data. The foams are formed based on the same principle: minimizing the area for the same amount of mass. On the other hand, cell wall area is not the only important influencing parameter on the mechanical properties, but topology has the same level of importance. The total area of various unit cells are presented in Fig. 3. The following relationships can be established for the wall surface area of the unit cell types:

$A_{\mathrm{WP}}<A_{\mathrm{K}}<A_{\mathrm{TC}}<A_{\mathrm{O}}<A_{\mathrm{RC}}$,

where WP, K, TC, O, and RC subscripts denote the Weaire-Phelan, Kelvin, truncated cube, octahedral, and 
Foam density: $2 \times 10^{-4} \mathrm{~g} / \mathrm{mm}^{3}$
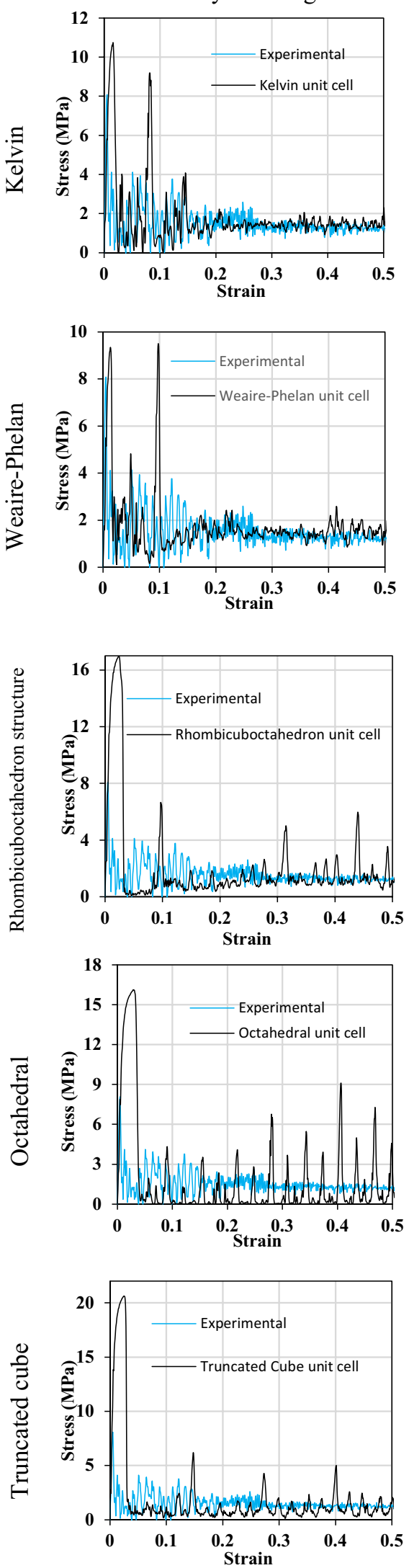

Foam density: $3 \times 10^{-4} \mathrm{~g} / \mathrm{mm}^{3}$
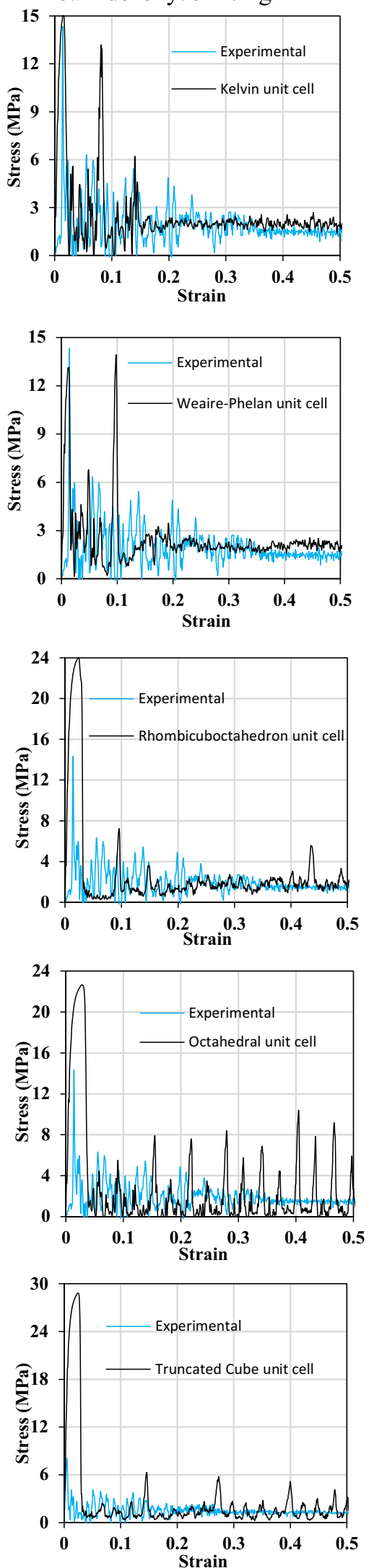

Foam density: $5 \times 10^{-4} \mathrm{~g} / \mathrm{mm}^{3}$
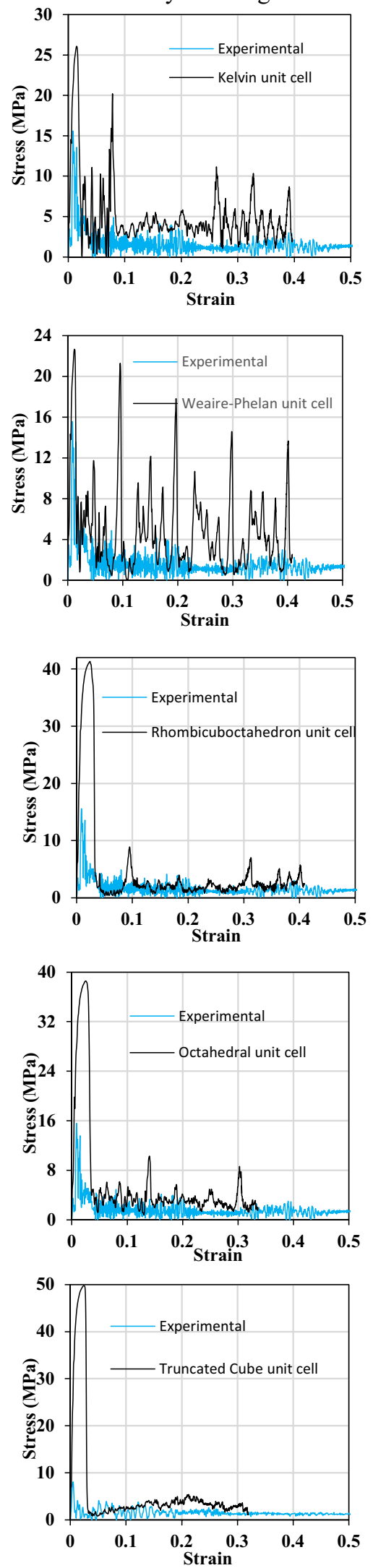

Fig. 7 Numerical impact results of different lattice structures compared to experimental impact results 

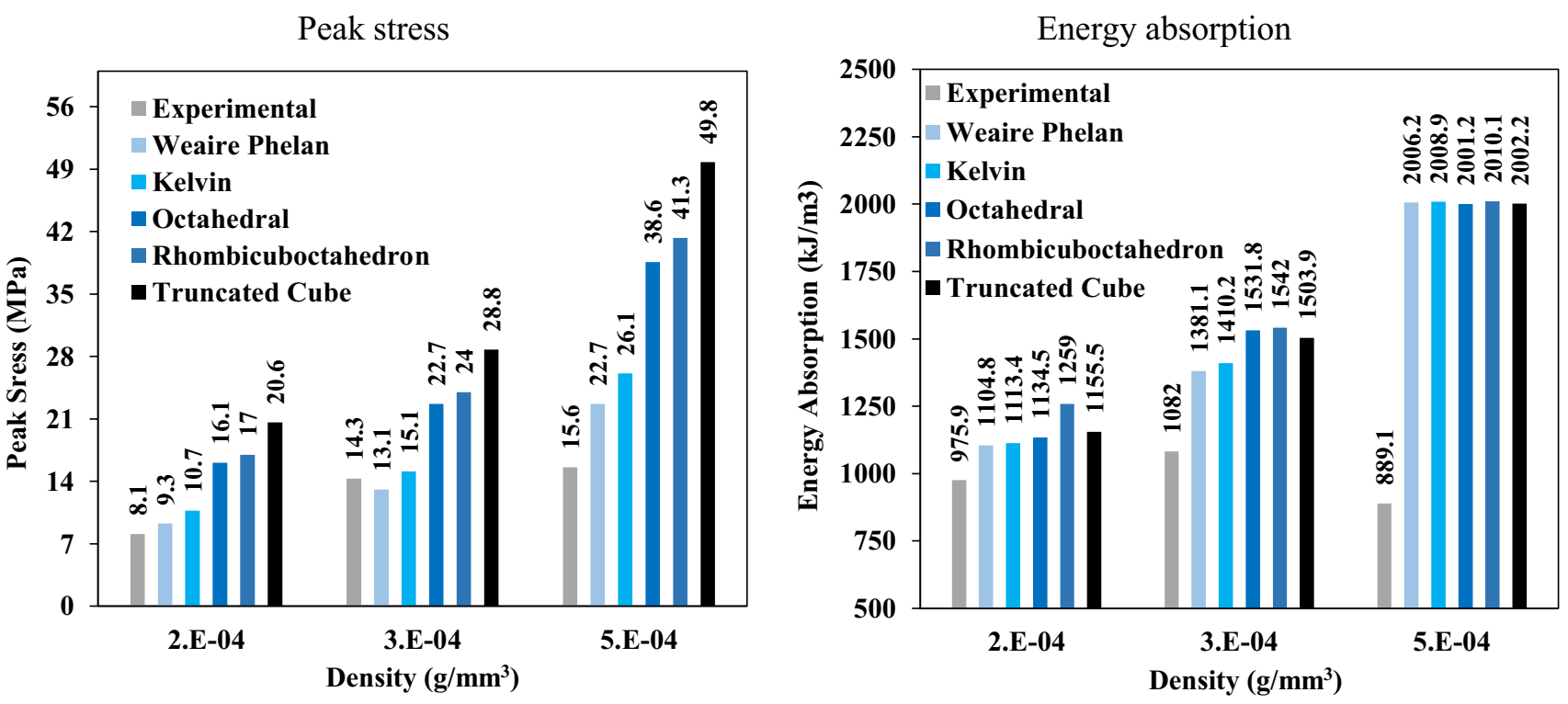

Fig. 8 Numerical and experimental magnitude of peak stress and energy absorption

rhombicuboctahedron unit cells. The first peak stress of different unit cells in all different densities have the following order:

$\mathrm{FPS}_{\mathrm{WP}}<\mathrm{FPS}_{\mathrm{K}}<\mathrm{FPS}_{\mathrm{O}}<\mathrm{FPS}_{\mathrm{RC}}<\mathrm{FPS}_{\mathrm{TC}}$,

As for the energy absorption capacity of low- and medium- density foams (Fig. 8):

$\mathrm{EA}_{\mathrm{WP}}<\mathrm{EA}_{\mathrm{K}}<\mathrm{EA}_{\mathrm{TC}}<\mathrm{EA}_{\mathrm{O}}<\mathrm{EA}_{\mathrm{RC}}$.

As it can be seen by comparing Eqs. (1) and (3), the order of the surface area of different unit cells is identical to the order of energy absorption capacity. The main mechanism of energy absorption in cells is through plastic deformation. This implies that energy absorption capacity is highly dependent on the cell wall area in such a way that high unit cell surface area leads to high energy absorption capacity. It must be noted that the response of foam specimens approaches that of base metal by increasing the foam density. Therefore, stress-strain curves of foam specimens with high values of density are relatively close to each other. As can be seen in the density effect diagrams in Fig. 8, as the density increases, the energy capacity of different topologies get closer to one another. Therefore, at high densities, the effect of the cellular structure geometry on the energy absorption capacity of that structure decreases. Moreover, by comparing the energy absorption results of different lattice structures at the density of $5 \times 10^{-4} \mathrm{~g} / \mathrm{mm}^{3}$ with the experimental test results, it can be concluded that the energy absorption capacity of lattice structures is much greater than that of the foam made of cells with random distribution. This can be attributed to better distribution of stress in the lattice structures which have regular cell distribution in their microstructure as compared to manufactured foam specimens which have random cell distribution.

A comparison between experimental data and numerical simulation is done in Table 3. As it can be seen, the models based on Kelvin and Weaire-Phelan unit cells predict peak stresses comparable to experimental results. On the other hand, numerical models based on truncated cube cell

Table 3 Results of numerical analysis compared to experimental test

\begin{tabular}{|c|c|c|c|c|c|c|c|}
\hline & Density $\left(\mathrm{g} / \mathrm{mm}^{3}\right)$ & Experimental & Kelvin & Weaire Phelan & Octahedral & $\begin{array}{l}\text { Rhombicu- } \\
\text { boctahedron }\end{array}$ & Truncated cube \\
\hline \multirow[t]{3}{*}{ Peak stress (MPa) } & $2 \times 10^{-4}$ & 8.1 & 10.7 & 9.3 & 16.1 & 17 & 20.6 \\
\hline & $3 \times 10^{-4}$ & 14.3 & 15.1 & 13.1 & 22.7 & 24 & 28.8 \\
\hline & $5 \times 10^{-4}$ & 15.6 & 26.1 & 22.7 & 38.6 & 41.3 & 49.8 \\
\hline \multirow[t]{3}{*}{ Energy absorption $\left(\mathrm{kJ} / \mathrm{m}^{3}\right)$} & $2 \times 10^{-4}$ & 975.9 & 1113.4 & 1104.8 & 1134.5 & 1259 & 1155.5 \\
\hline & $3 \times 10^{-4}$ & 1082 & 1410.2 & 1381.1 & 1531.8 & 1542 & 1503.9 \\
\hline & $5 \times 10^{-4}$ & 889.1 & 2008.9 & 2006.2 & 2001.2 & 2010.1 & 2002.2 \\
\hline
\end{tabular}


experience the highest peak stress. Rhombicuboctahedron and octahedral cell structures provide a mid-range peak stress. For foam specimens with the densities of $2 \times 10^{-4}$, $3 \times 10^{-4}$, and $5 \times 10^{-4}$, the least difference in peak stresses predicted by the numerical model on the one hand and the peak stress measured from experimental stress-strain curves on the other hand belonged to the Weaire-Phelan (14.8\%), Kelvin (5.6\%), and Weaire-Phelan (45.5\%) models, respectively. For energy absorption prediction in foam specimens with the densities $2 \times 10^{-4}, 3 \times 10^{-4}$, and $5 \times 10^{-4}$, the least difference corresponds to Weaire-Phelan (13.2\%), Weaire-Phelan (27.6\%) and Weaire-Phelan (125.6\%) models, respectively. In summary, the Kelvin and Weaire-Phelan lattices provided the most similar results to the experimental data obtained from foam specimens. It is worth mentioning that as compared to Weaire-Phelan model, the Kelvin model presented a smoother response in high impact velocities.

After studying the behavior of lattice structures at a constant impact velocity of $3.7 \mathrm{~m} / \mathrm{s}$ and comparing their results with the experimental results, the behavior of lattice structures under impact loading at higher impact velocities of 10 and $20 \mathrm{~m} / \mathrm{s}$ was also investigated. The stress-strain diagrams of different topologies for three densities of $2 \times 10^{-4}$, $3 \times 10^{-4}$, and $5 \times 10^{-4} \mathrm{~g} / \mathrm{mm}^{3}$ are illustrated in Fig. 9. As expected, by increasing the impact velocity from 3.7 to $20 \mathrm{~m} / \mathrm{s}$, energy absorption capacity and the first peak stress increased (Fig. 10). The trends of stress-strain diagrams are different for different topologies. As compared to other structures, the Kelvin topology shows the most uniform behavior in its stress-strain diagram, especially in the plateau region. The minimum value of first peak stress at all impact velocities and foam densities belongs to Weaire-Phelan lattice structure. However, among all the structures, this structure shows the most non-uniform behavior with the highest number of sharp peaks in its stress-strain curve. Increasing the impact velocity in Weaire-Phelan lattice structure in all densities leads to appearance of several sharp peaks in the stress-strain diagram. The number of these sharp peaks are the highest for the impact velocity of $10 \mathrm{~m} / \mathrm{s}$. More particularly, at the density of $5 \times 10^{-4} \mathrm{~g} / \mathrm{mm}^{3}$, almost no fluctuations are observed in the stress-strain diagram of Weaire-Phelan structure under the impact velocity of $20 \mathrm{~m} / \mathrm{s}$. The rhombicuboctahedron and octahedral structures have very close first peak stress values in all the foam densities and impact velocities (the rhombicuboctahedron structure has slightly higher first peaks stress than the octahedral), see Fig. 10. However, due to the different behavior of these two structures in the plateau region, they have different levels of energy absorption capacity. As it can be seen in Fig. 10, the truncated cube topology has the highest first peak stress among all structures at all impact velocities and at all densities. This can be attributed to its high stiffness, as it possesses several walls aligned with loading direction. A noteworthy point is the behavior of lattice structures at high density and low impact velocity, where the behavior of lattice structure is independent from the topology geometry (Fig. 10).

The dissimilar behaviors of different lattice structures are rooted in their geometric differences, which cause differences in the distribution of force between the cell walls and eventually their collapse. The order of first peak stress for different topologies was similar at different densities, while the order of energy absorption capacity for different topologies was different at different densities. This is due to the fact that when the first peak stress is formed in the stress-strain diagram, the cells have not yet collapsed, and the failure mode and different paths different unit cell types take to deform after collapse has not affected cellular structure behavior.

\section{Conclusions}

In this study, failure mechanism and stress-strain behavior of closed-cell foams under low velocity impact was studied experimentally and numerically. Closed-cell lattice structures based on five different unit cell types (Kelvin, Weaire-Phelan, octahedral, rhombicuboctahedron, and truncated cube) were generated for FE analysis and their mechanical behaviors were studied and compared. The numerical results were also compared to the experimental results. The effect of two important parameters: impact velocity and foam density were studied. The results showed that the unit cell micro-architecture has a significant role in determining the behavior of the lattice structure. The lattice structures with high fractions of vertical walls (truncated cube and rhombicuboctahedron) showed higher stiffness values as compared to lattice structures with high ratio of oblique walls (Weaire-Phelan and Kelvin). However, as for the energy absorption capacity, other factors were important. The lattice structures with high cell wall surface area had higher energy absorption capacities as compared to lattice structures with low surface area.

The post-failure deformation of structures was also highly dependent on the geometry of the unit cell. The initiation of failure of lattice structures based on Kelvin and Weaire-Phelan unit cells was from the upper part of the lattice structure which came into contact with the impactor first. However, in other topologies, the failure initiation started from the central part of the lattice structure. The maximum peak stress was observed in the truncated cube lattice structure which had the highest ratio of vertical walls. The results showed that, especially at high densities, the lattice structures which are based on regular unit cells have energy absorption capacities higher than foam structures which have random distribution of cells. The results showed that, among all lattice structures, the Kelvin topology presents the mechanical behavior most similar to that of 
Foam density: $2 \times 10^{-4} \mathrm{~g} / \mathrm{mm}^{3}$
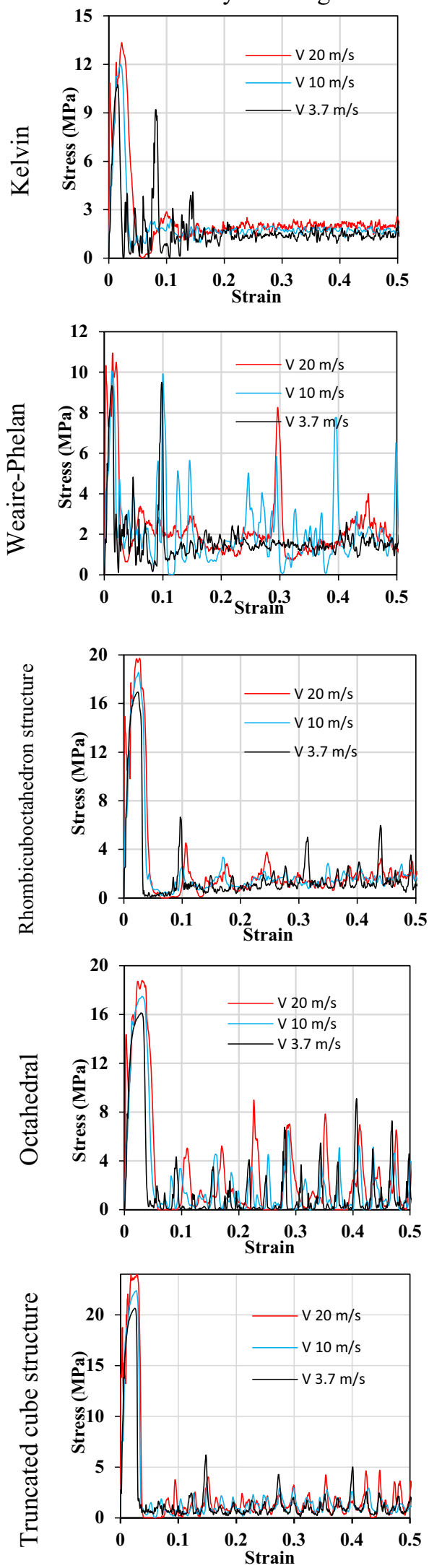

Foam density: $3 \times 10^{-4} \mathrm{~g} / \mathrm{mm}^{3}$
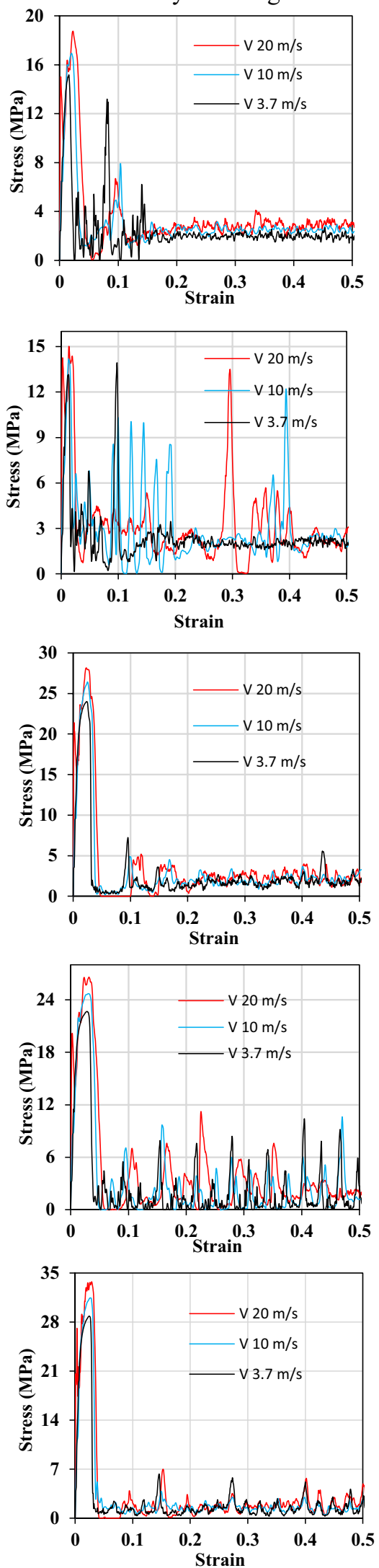

Foam density: $5 \times 10^{-4} \mathrm{~g} / \mathrm{mm}^{3}$
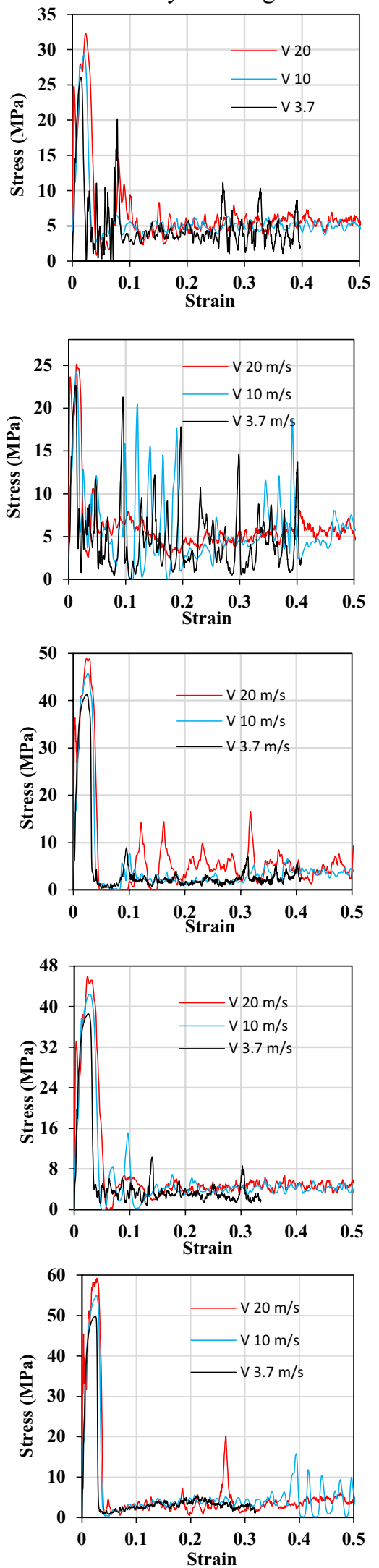

Fig. 9 FE simulation results for three different impact velocities 

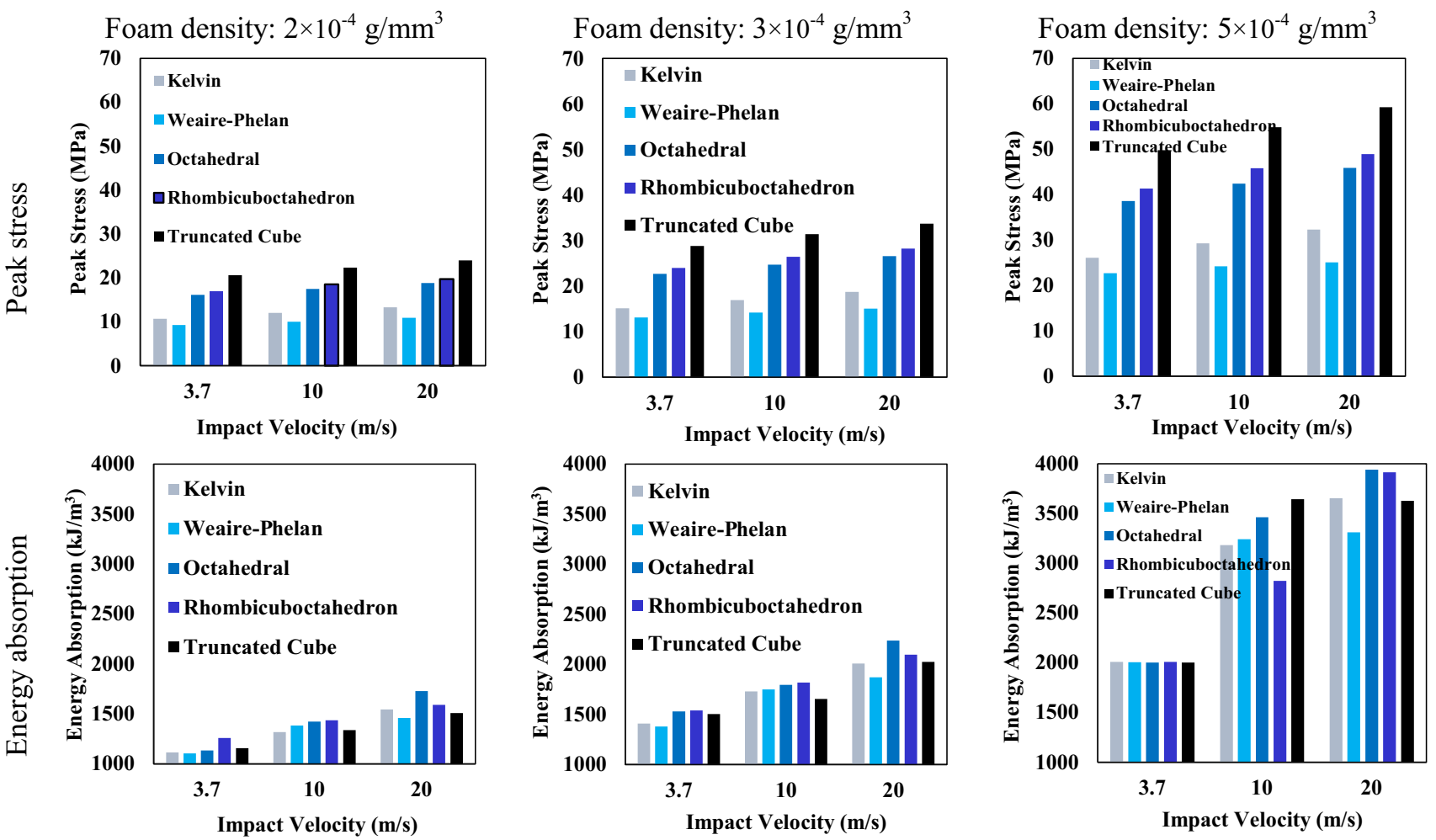

Fig. 10 Peak stress and energy absorption based on different types of unit cell structures for three different impact velocities

experiments. However, in different impact velocities and foam densities, different lattice types show different advantages in terms of energy absorption and initial stiffness. Therefore, depending on the application, one can choose the appropriate lattice structure type for manufacturing a regular lattice structure using advanced manufacturing technologies such as additive manufacturing. Finally, the results of this study showed that constructing lattice structures based on regular unit cells is a very accurate and cost-effective method for modeling the behavior of closed-cell foams.

Acknowledgements The work presented in this paper was supported by a grant from the Iran National Science Foundation (Grant number 97004398).

\section{Declarations}

Conflict of interest The authors declare no conflict of interest.

Ethical approval This article does not contain any studies with human participants or animals performed by any of the authors.

Open Access This article is licensed under a Creative Commons Attribution 4.0 International License, which permits use, sharing, adaptation, distribution and reproduction in any medium or format, as long as you give appropriate credit to the original author(s) and the source, provide a link to the Creative Commons licence, and indicate if changes were made. The images or other third party material in this article are included in the article's Creative Commons licence, unless indicated otherwise in a credit line to the material. If material is not included in the article's Creative Commons licence and your intended use is not permitted by statutory regulation or exceeds the permitted use, you will need to obtain permission directly from the copyright holder. To view a copy of this licence, visit http://creativecommons.org/licenses/by/4.0/.

\section{References}

1. Ashby M, Evans A, Fleck N, Gibson L, Hutchinson J, Wadley H. Metal foams: a design guide. Mater Des. 2002;23:119.

2. Banhart J. Manufacture, characterisation and application of cellular metals and metal foams. Prog Mater Sci. 2001;46(6):559-632.

3. Evans AG, Hutchinson JW, Fleck NA, Ashby MF, Wadley HNG. The topological design of multifunctional cellular metals. Prog Mater Sci. 2001;46(3):309-27.

4. Peroni M, Solomos G, Pizzinato V. Impact behaviour testing of aluminium foam. Int J Impact Eng. 2013;53:74-83.

5. Singh R, Lee PD, Lindley TC, Kohlhauser C, Hellmich C, Bram M, Imwinkelried T, Dashwood RJ. Characterization of the deformation behavior of intermediate porosity interconnected Ti foams using micro-computed tomography and direct finite element modeling. Acta Biomater. 2010;6(6):2342-51.

6. Torkestani A, Sadighi M, Hedayati R. Effect of material type, stacking sequence and impact location on the pedestrian head injury in collisions. Thin Walled Struct. 2015;97:130-9.

7. Li Q, Maharaj R, Reid S. Penetration resistance of aluminium foam. Int J Veh Des. 2005;37:175-84. 
8. Ruan D, Lu G, Wang B, Yu TX. In-plane dynamic crushing of honeycombs-a finite element study. Int J Impact Eng. 2003;28(2):161-82.

9. Silva MJ, Hayes WC, Gibson LJ. The effects of non-periodic microstructure on the elastic properties of two-dimensional cellular solids. Int J Mech Sci. 1995;37(11):1161-77.

10. Wang Z, Ma H, Zhao L, Yang G. Studies on the dynamic compressive properties of open-cell aluminum alloy foams. Scripta Mater. 2006;54(1):83-7.

11. Wang Z, Shen J, Lu G, Zhao L. Compressive behavior of closedcell aluminum alloy foams at medium strain rates. Mater Sci Eng A. 2011;528(6):2326-30.

12. Hedayati R, Hosseini-Toudeshky H, Sadighi M, Aghdam M, Zadpoor A. Multiscale modeling of fatigue crack propagation in additively manufactured porous biomaterials. Int J Fatigue. 2018;113: 416-27.

13. Hedayati R, Rubio-Carpio A, Luesutthiviboon S, Ragni D, Avallone F, Casalino D, Zwaag S. Role of polymeric coating on metallic foams to control the aeroacoustic noise reduction of airfoils with permeable trailing edges. Materials. 2019;12:1087.

14. Gibson LJ, Ashby MF. Cellular solids: structure and properties. Cambridge solid state science series. 2nd ed. Cambridge: Cambridge University Press; 1997.

15. Brakke KA. The surface evolver. Exp Math. 1992;1(2):141-65.

16. Sir Thomson W. On the division of space with minimum partitional area. Acta Math. 1887;11(1):121-34.

17. Weaire D, Phelan R. A counter-example to Kelvin's conjecture on minimal surfaces. Philos Mag Lett. 1994;69(2):107-10.

18. Grenestedt JL, Tanaka K. Influence of cell shape variations on elastic stiffness of closed cell cellular solids. Scripta Mater. 1998;40(1):71-7.

19. Grenestedt JL, Bassinet F. Influence of cell wall thickness variations on elastic stiffness of closed-cell cellular solids. Int J Mech Sci. 2000;42(7):1327-38.

20. Meguid S, Cheon S, Elabbasi N. FE modeling of deformation localization in metallic foams. Finite Elem Anal Des. 2002;38:631-43.

21. Czekanski A, Attia M, Meguid S, Elbestawi M. On the use of a new cell to model geometric asymmetry of metallic foams. Finite Elem Anal Des. 2005;41:1327-40.

22. Czekanski A, Elbestawi M, Meguid S. On the FE modeling of closed-cell aluminum foam. Int J Mech Mater Des. 2005;2:23-34.

23. Kim A, Tunvir K, Jeong GD, Cheon SS. A multi-cell FE-model for compressive behaviour analysis of heterogeneous Al-alloy foam. Model Simul Mater Sci Eng. 2006;14:933-45.

24. Daxner T, Bitsche RD, Böhm HJ. Micromechanical models of metallic sponges with hollow struts. Mater Sci Forum. 2007;539-543:1857-62.

25. Nammi SK, Myler P, Edwards G. Finite element analysis of closed-cell aluminium foam under quasi-static loading. Mater Des. 2010;31(2):712-22.

26. Hedayati R, Sadighi M. A micromechanical approach to numerical modeling of yielding of open-cell porous structures under compressive loads. J Theor Appl Mech. 2016;54:769.
27. Mohammadi K, Movahhedy MR, Shishkovsky I, Hedayati R. Hybrid anisotropic pentamode mechanical metamaterial produced by additive manufacturing technique. Appl Phys Lett. 2020;117(6):061901.

28. Ghavidelnia N, Bodaghi M, Hedayati R. Femur auxetic metaimplants with tuned micromotion distribution. Materials. 2021;11(3):034057.

29. Aldoshan A, Khanna S. Effect of relative density on the dynamic compressive behavior of carbon nanotube reinforced aluminum foam. Mater Sci Eng A. 2017;689:17-24.

30. Dass Goel M, Matsagar VA, Gupta AK, Marburg S. Strain rate sensitivity of closed cell aluminium fly ash foam. Trans Nonferr Met Soc China. 2013;23(4):1080-9.

31. Giorgi M, Carofalo A, Dattoma V, Nobile R, Palano F. Aluminium foam structural modelling. Comput Struct. 2010;88:25-35.

32. Han M, Cho J. Impact damage behavior of sandwich composite with aluminum foam core. Trans Nonferr Met Soc China. 2014;24:42-6.

33. Hasan MDA. An improved model for Fe modeling and simulation of closed cell Al-alloy foams. Adv Mater Sci Eng. 2010; 567390: $1-12$.

34. Kadkhodapour J, Raeisi S. Micro-macro investigation of deformation and failure in closed-cell aluminum foams. Comput Mater Sci. 2014;83:137-48.

35. Liu C, Zhang Y. Modelling mechanical behavior of aluminium foam under compressive loading using representative volume element method. In: 5th European conference on computational mechanics, Barcelona, Spain, July, pp. 20-5. 2013.

36. Wang Y, Zhai X, Yan J, Ying W, Wang W. Experimental, numerical and analytical studies on the aluminum foam filled energy absorption connectors under impact loading. Thin Walled Struct. 2018;131:566-76.

37. Epasto G, Distefano F, Gu L, Mozafari H, Linul E. Design and optimization of metallic foam shell protective device against flying ballast impact damage in railway axles. Mater Des. 2020;196:109120.

38. Han Z, Li C, Deng Y, Liu J. The analysis of anti-collision performance of the fender with offshore wind turbine tripod impacted by ship and the coefficient of restitution. Ocean Eng. 2019;194:106614

39. Hedayati R, Jedari Salami S, Li Y, Sadighi M, Zadpoor AA. Semianalytical geometry-property relationships for some generalized classes of pentamodelike additively manufactured mechanical metamaterials. Phys Rev Appl. 2019;11(3):034057.

40. Hedayati R, Sadighi M, Mohammadi-Aghdam M, HosseiniToudeshky H. Comparison of elastic properties of open-cell metallic biomaterials with different unit cell types. J Biomed Mater Res B Appl Biomater. 2018;106(1):386-98.

41. Su XY, Yu TX, Reid SR. Inertia-sensitive impact energy-absorbing structures part II: effect of strain rate. Int J Impact Eng. 1995;16(4):673-89. 